\title{
Anti-inflammatory and Antioxidant Activities of Cucumis sativus Leaves
}

\author{
Fatema Nasrin ${ }^{1}$, Israt Jahan Bulbul ${ }^{1}$, Fahima Aktar ${ }^{2}$ and Mohammad A. Rashid ${ }^{2}$ \\ ${ }^{1}$ Department of Pharmacy, Southeast University, Banani, Dhaka-1213, Bangladesh \\ ${ }^{2}$ Phytochemical Research Laboratory, Department of Pharmaceutical Chemistry, University of Dhaka, \\ Dhaka-1000, Bangladesh
}

Received: June 10, 2015; Accepted: July 05, 2015; Published (Web): July 21, 2015

\begin{abstract}
This study was carried out to evaluate the anti-inflammatory and antioxidant activities of Cucumis sativus Linn. (Family: Cucurbitaceae) leaves. The methanolic extract of C. sativus leaves (MCS) was investigated for antiinflammatory activities in Long Evans rat model at two different doses of 150 and $250 \mathrm{mg} / \mathrm{kg}$ body weight and the effects were compared with the standard, indomethacin $(10 \mathrm{mg} / \mathrm{kg}$ body weight). It exhibited highest antiinflammatory activity at the dose $250 \mathrm{mg} / \mathrm{kg}$. In the formalin test, the extract at both doses (150 and $250 \mathrm{mg} / \mathrm{kg}$ body weight) significantly prevented the increase in volume of paw edema $(\mathrm{P}<0.05$ and $\mathrm{P}<0.001)$. In carrageenan-induced paw edema test the MCS significantly $(\mathrm{P} \leq 0.001)$ reduced inflammation by $57.35 \%(150 \mathrm{mg} / \mathrm{kg}$ body weight $)$ and $72.06 \%$ (250 mg/kg body weight) in comparison to the standard drug, indomethacin $(79.41 \%)$ at the end of $5 \mathrm{~h}$. MCS was also screened for DPPH scavenging activity, total antioxidant capacity, reducing ability as well as total phenolics content to assess its antioxidant potential. Total phenolic content and total antioxidant capacity of MCS were found to be $262.31 \mathrm{mg} / \mathrm{g}$ equivalent of gallic acid and $267.2 \mathrm{mg} / \mathrm{g}$ equivalent of ascorbic acid, respectively. The $\mathrm{IC}_{50}$ of free radical scavenging of DPPH was $13.06 \mu \mathrm{g} / \mathrm{ml}$ while that of standard ascorbic acid was $13.17 \mu \mathrm{g} / \mathrm{ml}$. The reducing power of MCS was found to be concentration dependent.
\end{abstract}

Key words: Anti-inflammatory, carrageenan, paw edema, antioxidant.

\section{Introduction}

Although inflammation is a defense mechanism, an uncontrolled and persistent inflammation may act as an etiologic factor for many chronic illnesses (Kumar et al., 2004). Worldwide, there is an increasing concern in finding new anti-inflammatory remedies, which are not only effective, but also nontoxic; in this respect plant extracts are in focus. Recently special scientific interest has been focused on natural foods, medicinal plants and phytoconstituents to utilize their well-known antioxidant power (Kukic et al., 2006). The free radicals in human body develops a great number of pathological states like inflammation, atherosclerosis, stroke, heart disease, diabetes mellitus, multiple sclerosis, cancer, Parkinson's disease, Alzheimer's disease, etc. (Ozgen et al., 2006).

Cucumis sativus Linn. (Family: Cucurbitaceae) is an annual, rather coarse, fleshy, prostrate or climbing vine. Different parts of this plant is traditionally used in headache, as cooling and diuretic, nutritive and demulcent, and emetic in acute indigestion in children (Hisahiro et al., 2008). Several studies have shown multiple biological activities of different parts of $C$. sativus. These include antidiabetic (Karthiyayini et al., 2009), antiulcer (Swapnil et al., 2012), moisturizing (Prashant et al., 2005), antioxidant and analgesic properties (Kumar et al., 2006) of the fruit extracts. The seed extracts were found effective on controlling the loss of body weight in diabetic rats (Minaiyan et al., 2006) and against tapeworms (Elisha et al., 2006). Cytotoxic, antifungal (Joysree et al., 2012) and antibacterial (Tang et al., 2010) activities have been reported from leaves and stems extracts. Chemical studies have demonstrated the presence of cucurbitasides B, C and ferredoxin in leaves (Joshi, 2003; Nadkarni and Nadkarni, 2006) and $\alpha$ - and $\beta$-amyrins, sitosterol and cucurbitasides (Abou-Zaid et al., 2001) in seeds. No report on antiinflammatory activity was found for the $C$. sativus leaves.

So, an attempt was made to assess scientifically the in vivo anti-inflammatory and in vitro antioxidant activities of methanolic extract of $C$. sativus leaves.

\section{Materials and Methods}

Collection of sample and preparation of extract: The leaves of $C$. sativus were collected from Gazipur in the 
month of March, 2012. The plant was taxonomically identified in Bangladesh National Herbarium, Dhaka, Bangladesh, where a voucher specimen (DACB no-34479) has been deposited. The fresh leaves were first washed with water to remove adhering dirt and then dried at $45{ }^{\circ} \mathrm{C}$ for $36 \mathrm{hrs}$ in an electric oven, then powdered with a mechanical grinder, passed through sieve \# 40 and stored in a tight container. The dried powdered material $(1 \mathrm{~kg})$ was taken in a clean, flat bottom glass container and soaked in methanol for seven days. The whole mixture then underwent a coarse filtration by a piece of clean, white cotton material. The total filtrate was concentrated to dryness, in vacuo at $40{ }^{\circ} \mathrm{C}$ to render the methanol extract (390 g) of brownish red color.

Animals: Long Evans rats of either sex weighing about 135-150 g were used for the experiments. The rats were purchased from the Animal Resources Branch of the International Centre for Diarrhoeal Disease and Research, Bangladesh (ICDDR,B). They were kept in standard environmental condition (at $24^{\circ} \mathrm{C}$ temperature, $55-65 \%$ relative humidity and $12 \mathrm{~h}$ light/12 h dark cycle) for one week for acclimation after their purchase and fed with ICDDR,B formulated rodent food and water ad. libitum. The set of rules followed for animal experiment were approved by the institutional animal ethical committee (Zimmermann, 1983).

Drugs and chemicals: The active drugs indomethacin, was a generous gift samples from Square Pharmaceuticals Ltd., Bangladesh. Formalin and carrageenan was obtained from $\mathrm{CDH}$, India. Tween-80 was obtained from $\mathrm{BDH}$ Chemicals, UK. Normal saline solution was purchased from Beximco Infusion Ltd., Bangladesh. Ammonium molybdate (Merck, Germany), sodium phosphate (BDH, England), potassium ferricyanide $\left[\mathrm{K}_{3}\left\{\mathrm{Fe}(\mathrm{CN})_{6}\right\}\right]$ trichloroacetic acid $\left(\mathrm{CCl}_{3} \mathrm{COOH}\right)$, Folin-Ciocalteu reagent, gallic acid $\left[\mathrm{C}_{6} \mathrm{H}_{2}(\mathrm{OH})_{3} \mathrm{COOH}\right]$, ascorbic acid and other chemicals used were of analytical reagent grade.

Instruments: The molecular absorption spectra and absorbance at specific wavelengths were recorded with a HACH DR 4000U UV-visible spectrophotometer equipped with quartz cells of $1-\mathrm{cm}$ light path.

Oral toxicity tests: Long Evans rats (135 - $150 \mathrm{~g})$ were randomly divided into nine groups of five animals each. The animals were starved for $12 \mathrm{~h}$ prior to testing. Eight doses of the extract, were administered by oral administration to eight groups of the animals, separately. The animals in the control group received $0.2 \mathrm{ml}$ distilled water. All animals were observed for $24 \mathrm{~h}$ and general symptoms of toxicity and mortality were recorded (Amida et al., 2007).

In vivo anti-inflammatory activity:

Carrageenan-induced paw edema: The animals were divided into five groups containing five rats in each. Acute inflammation was produced by subplantar injection of 0.1 $\mathrm{ml}$ of $1 \%$ suspension of carrageenan with $2 \%$ gum acacia in normal saline, in the right hind paw of the rats, $1 \mathrm{~h}$ after oral administration of MCS at doses of 150 and 250 $\mathrm{mg} / \mathrm{kg}$, b.w. The paw volume was measured at 1, 2, 3, 4 and $5 \mathrm{~h}$ after the carrageenan injection using micrometer screw gauge. The difference between the two readings was taken as the volume of edema. Indomethacin suspended in $2 \%$ gum acacia was used as the standard drug. The percentage inhibition of inflammation was computed using the following formula (Adedapo et al., 2008):

$\%$ inhibition $=\left\{\left(D_{0}-D_{t}\right) / D_{0}\right\} \times 100 \%$

where, $D_{0}=$ the average inflammation (hind paw edema) of the control group; $D_{t}=$ the average inflammation (hind paw edema) of the treated group.

Formalin-induced paw edema: Following the method described by Sharma et al. (2010), paw edema was induced by formaldehyde to assay the anti-inflammatory activity of MCS. The experimental rats in control group received 5\% formalin. $20 \mu \mathrm{l}$ of $5 \%$ formalin was injected into the dorsal surface of the right hind paw at $60 \mathrm{~min}$ after administration of two different doses of MCS (150 and $250 \mathrm{mg} / \mathrm{kg}$, b.w.) and indomethacin $(10 \mathrm{mg} / \mathrm{kg}$, b.w.). The increase in paw diameter was measured using vernier caliper. The difference in edema of the right hind paw and the left hind paw indicates inflammation. Measurement was done immediately before and after $1-5 \mathrm{~h}$ following formalin injection.

In vitro antioxidant study: In vitro antioxidative abilities of MCS were screened in terms of total phenol content, total antioxidant capacity, DPPH radical scavenging activity and reducing power.

Assay for total phenolic content in MCS: The total phenolic content of the extract was determined using Folin-Ciocalteu reagent (Yu et al., 2010). The content of total phenol in the extracts was calculated from regression equation of the calibration curve $(y=0.0138 x+0.1276$, 
$\left.\mathrm{R}^{2}=0.988\right)$ and was expressed as gallic acid equivalents (GAE).

Assay for total antioxidant capacity: The antioxidant activity of the extract was evaluated by the phosphomolybdenum method (Prieto et al., 1999). The assay is based on the reduction of Mo (VI)-Mo (V) by the extract and subsequent formation of a green phosphate/Mo (V) complex at acidic,. $\mathrm{pH}$. The total antioxidants in the extracts was calculated from regression equation of the calibration curve $\left(y=0.0043 x+0.1503, R^{2}=0.8874\right)$ and was expressed as ascorbic acid equivalents (AAE).

DPPH free radical scavenging activity: The free radical scavenging activity of the extracts, based on the scavenging activity of the stable 1,1-diphenyl-2picrylhydrazyl (DPPH) free radical was determined by the method described by Braca et al. (2001). The percentage inhibitory activity was calculated from the following equation:

$$
\% \text { of inhibition }=\left[\left(A_{0}-A_{1}\right) / A_{0}\right] \times 100
$$

where, $A_{o}$ is the absorbance of the control, and $A_{1}$ is the absorbance of the extract/ standard. $\mathrm{IC}_{50}$ value was calculated from the equation of line obtained by plotting a graph of concentration $(\mu \mathrm{g} / \mathrm{ml})$ versus $\%$ inhibition.

Reducing power: The reducing power of the extract was determined according to the method described by Oyaizu et al. (1986). Here the transformation of $\mathrm{Fe}^{3+}$ to $\mathrm{Fe}^{2+}$ was investigated using ascorbic acid as standard. Increase in absorbance of the reaction mixture indicated greater reducing power.

Statistical analysis: All the values in the test are expressed as mean \pm standard deviation (SD). The data were statistically analyzed by ANOVA (one way of analysis of variance) and post-hoc Dunnett's tests with the
Statistical Package for Social Sciences (SPSS 16.0, USA) program. Dissimilarity between the means of the various groups were measured significant at $* \mathrm{P}<0.05$, $* * \mathrm{P}<0.01$ and $* * * \mathrm{P}<0.001$.

\section{Results and Discussion}

Oral administration of the methanolic extract of leaf of $C$. sativus produced no mortality, even no visible signs of toxicity in the animals except for an initial huddling observed at the highest dose of $4 \mathrm{~g} / \mathrm{kg}$ body weight. In addition, no toxic symptoms and reduction in food and water intake were observed during the period of experiment.

In the carrageenan-induced edema test, the higher dose $(250 \mathrm{mg} / \mathrm{kg}$ of body weight) produced significant $(\mathrm{P}<.001)$ inhibition $(48 \%)$ of the paw edema compared to the control after $3 \mathrm{~h}$ of carrageenan injection. Both the doses of the extract significantly inhibited the edema at 5 $\mathrm{h}$ after carrageenan injection. At $150 \mathrm{mg} / \mathrm{kg}$ dose, $50 \%$ inhibition and at $250 \mathrm{mg} / \mathrm{kg}$ dose, $72.06 \%$ inhibition was observed. Indomethacin $(10 \mathrm{mg} / \mathrm{kg}$ of body weight $)$ significantly $(\mathrm{P}<.001)$ reduced paw edema after $2 \mathrm{~h}$ from carrageenan injection compared to MCS (Table 1).

Oral administration of MCS showed dose dependant inhibition $(\mathrm{P}<0.05)$ of edema in formalin test. It significantly inhibited the edema in rats at both doses (150 and $250 \mathrm{mg} / \mathrm{kg}$ ) from the $3^{\text {rd }}-5^{\text {th }}$ observation period and indomethacin showed maximum inhibition of edema as presented in Table 2.

The total phenolics content of MCS was found to be $262.31 \mathrm{mg} / \mathrm{g}$ equivalent of gallic acid. On the other hand, the total antioxidant capacity was observed as $267.2 \pm$ $0.22 \mathrm{mg} / \mathrm{g}$ equivalent of ascorbic acid for MCS.

Table 1. Anti-inflammatory activity of methanolic extract of $C$. sativus leaves (MCS) in carrageenan-induced paw edema in rats.

\begin{tabular}{lcccc}
\hline Group & Paw volume & Paw volume & \multicolumn{2}{c}{ Inhibition (\%) } \\
\cline { 4 - 5 } & increase $(\mathrm{cm})$ after & increase (cm) after & After 3h & After 5h \\
\hline Control (vehicle) & $3 \mathrm{~h}$ & $5 \mathrm{~h}$ & - & - \\
Indomethacin $(10 \mathrm{mg} / \mathrm{kg} \mathrm{bw})$ & $0.23 \pm 0.08 \pm 0.03 * * * 05$ & $0.14 \pm 0.01^{* * *}$ & 54.00 & 79.41 \\
MCS $(150 \mathrm{mg} / \mathrm{kg} \mathrm{bw})$ & $0.35 \pm 0.02$ & $0.29 \pm 0.01 * * *$ & 30.00 & 57.35 \\
MCS $(250 \mathrm{mg} / \mathrm{kg} \mathrm{bw})$ & $0.26 \pm 0.01^{* * *}$ & $0.19 \pm 0.01 * * *$ & 48.00 & 72.06 \\
\hline
\end{tabular}

All values are expressed as mean $\pm \mathrm{SD},(\mathrm{n}=5)$; One way analysis of variance (ANOVA) followed by Dunnet's test. $* * * \mathrm{P}<0.001$, significant compared to control. 
Table 2. Anti-inflammatory effect of methanolic extract of $C$. sativus leaves (MCS) in in formalin induced edema test in rats.

\begin{tabular}{lccccc}
\hline Groups & \multicolumn{5}{c}{ Paw edema volume $(\mathrm{cm})$ in hours } \\
\cline { 2 - 6 } & $1 \mathrm{~h}$ & $2 \mathrm{~h}$ & $3 \mathrm{~h}$ & $4 \mathrm{~h}$ & $5 \mathrm{~h}$ \\
\hline Control & $0.20 \pm 0.03$ & $0.17 \pm 0.02$ & $0.15 \pm 0.01$ & $0.13 \pm 0.01$ & $0.11 \pm 0.04$ \\
Indomethacin $(10 \mathrm{mg} / \mathrm{kg} \mathrm{bw})$ & $0.13 \pm 0.05^{*}$ & $0.13 \pm 0.03$ & $0.11 \pm 0.00^{* * *}$ & $0.08 \pm 0.04^{* * *}$ & $0.07 \pm 0.02^{* * *}$ \\
MCS, $150(\mathrm{mg} / \mathrm{kg} \mathrm{bw})$ & $0.19 \pm 0.01$ & $0.15 \pm 0.04$ & $0.13 \pm 0.02^{*}$ & $0.12 \pm 0.05^{*}$ & $0.10 \pm 0.01^{*}$ \\
MCS , 250 (mg/kg bw) & $0.16 \pm 0.03$ & $0.14 \pm 0.01$ & $0.12 \pm 0.00^{*}$ & $0.11 \pm 0.01 * * *$ & $0.08 \pm 0.01 * * *$ \\
\hline
\end{tabular}

All values are expressed as mean \pm SEM, $(n=5)$; One way analysis of variance (ANOVA) followed by Dunnet's test. *P $<0.05$, $* * * \mathrm{P}<0.001$, significant compared to control.

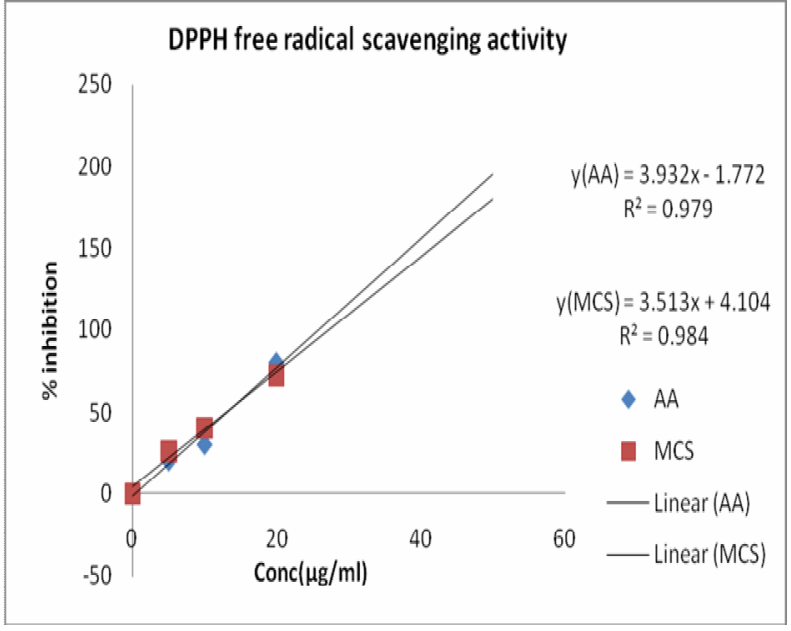

Figure1. DPPH free radical scavenging activity of MCS and ascorbic acid.

DPPH is most stable radical commonly used in antioxidant assays. The percentage (\%) scavenging of DPPH free radical was found to be concentration dependent, i.e. concentration of the extract between 5-100 $\mu \mathrm{g} / \mathrm{ml}$ greatly increased the inhibitory activity (Figure 1) with the $\mathrm{IC}_{50}$ value of $13.06 \mu \mathrm{g} / \mathrm{ml}$ for MCS while for standard ascorbic acid it was found to be $13.17 \mu \mathrm{g} / \mathrm{ml}$. For the measurement of the reductive ability, we investigated the $\mathrm{Fe}^{3+}$ to $\mathrm{Fe}^{2+}$ transformation in the presence of MCS compared with standard ascorbic acid as shown in figure 2. The reducing power of extracts was found to be concentration dependent.

\section{References}

Adedapo, A.A., Sofidiya, M.O., Maphosa, V., Moyo, B., Masika, P.J. and Afolayan, A.J. 2008. Anti-inflammatory and analgesic activities of the aqueous extract of Cussonia paniculata stem Bark. Rec. Nat. Prod. 2, 46-53.

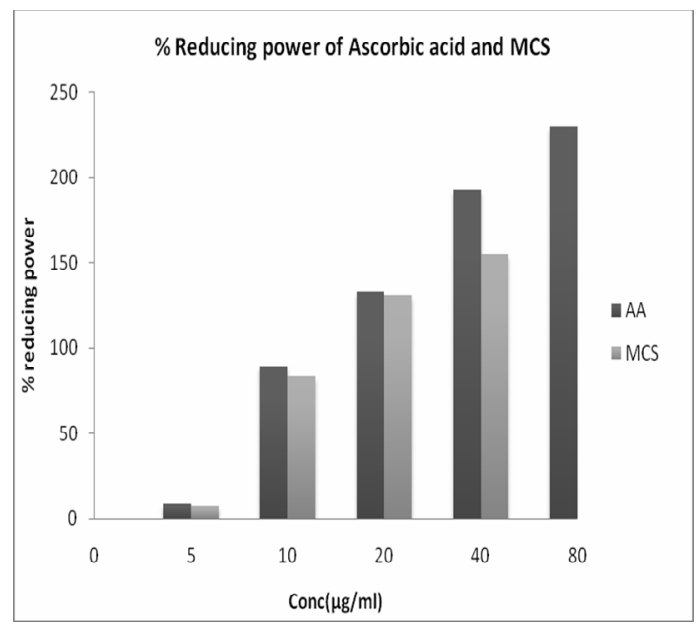

Figure 2. Comparison of reducing power of MCS and ascorbic acid.

Amida, M.B., Yemitan, O.K. and Adeyemi, O.O. 2007. Toxicological Assessment of the Aqueous Root Extract of Sanseviera libericaGerome and Labroy (Agavaceae). $J$. Ethnopharmacol. 113, 171-175.

Braca, A., Tommasi, N.D., Bari, L.D., Pizza, C., Politi, M. and Morelli, I. 2001. Natural anti-oxidants from plant material in phenolic compounds in food and their effects on health. J. Nat. Prod. 64, 892-895.

Elisha, E.E., Twaij, H.A.A., Ali, N.M., Tarish, J.H., Al-Omari, M.M. and Karim, S. 1987. The anti-helmintic activity of some Iraqi plants of the Cucurbitaceae. Pharma. Bio. 25, 153-157.

Hisahiro, K., Masaki, B. and Toru, O. 2008. Inhibitory Effect of Cucumis sativus on melanin production in melanoma B16 Cells by down regulation of tyrosinase expression. Planta. Med. 74, 1785-1788.

Joshi, S.G. 2003. Medicinal Plants, Oxford and IBH Publishing Co. Pvt. Ltd., New Delhi, pp. 157-158.

Joysree, D., Anusua, C., Subrata, K.B., Utpal, K.K., Syeda, R.S., Sheikh, Z.R. and Md, A.M. 2012. Cytotoxicity and Antifungal Activities of Ethanolic and Chloroform Extracts of Cucumis sativus Linn (Cucurbitaceae) Leaves and Stems. Res. J. Phytochem. 6, 25-30. 
Karthiyayini, T., Rajesh, K., Senthil, K.L.K., Sahu, R.K. and Roy, A. 2009. Evaluation of antidiabetic and hypolipidemic effect of Cucumis sativus fruit in streptozotocin-induced-diabetic rats. Biomed. Pharmacol. J. 2, 351-355.

Kukic, J., Petrovic, S. and Niketic, M. 2006. Antioxidant activity of four endemic Stachys taxa. Biol. Pharm. Bul. 29, 725-729.

Kumar, D., Kumar, S., Singh, J., Narender, Rashmi., Vashistha, B.D. and Singh, N. 2010. Free radical scavenging and analgesic activities of Cucumis sativus L. fruit extract. $J$. Young. Pharm. 2, 365-368.

Kumar, V. and Abbas, A.K. 2004. Fausto N (eds.) In: Robbins and Cotran pathologic basis of disease. $7^{\text {th }}$ ed. Philadelphia, Elsevier Saunders, pp. 47-86.

Nadkarni, A.K. and Nadkarni, K.M. 2005. Indian Materia Medica, Popular Prakashan, Bombay, pp. 403-404.

Oyaizu, M. 1986. Studies on product of browning reaction prepared from glucose amine. Jap. J Nutr. 44, 307-315.

Ozgen, U., Mavi, A., Terzi, Z., Yildirim, A., Coskun, M. and Houghton, P.J. 2006. Antioxidant properties of some medicinal Lamiaceae species. Pharm. Biol. 44, 107-112.

Phadke, K. 1988. In vivo and in vitro models for arthritis, Indian. Drugs. 25, 354-365.
Prashant, L.K., Hemant, R.J., Prasad, T. and Anantha, N.N. 2005. Cosmetics potentials of herbal extracts. Nat. Prod. Rad. 4, 315-321.

Prieto, P., Pineda, M. and Aguilar, M. 1999. Spectrophotometric quantitation of antioxidant capacity through the formation of a Phosphomolybdenum Complex: Specific application to the determination of vitamin E. Analyt. Biochem. 269, 337-341.

Singh, R., Singh, S., Kumar, S. and Arora, S. 2007. Studies on antioxidant potential of methanol extract/fractions of Acacia auriculiformis. Curr. Food. Chem. 103, 505.

Swapnil, S., Jaya, D., Meenakshi, A. and Sarvesh, P. 2012. Cytoprotection mediated antiulcer effect of aqueous fruit pulp extract of Cucumis sativus. Asian. Pacific. J. Tropi. Dis. 5, 61-67.

Tang, J., Meng, X., Liu, H., Zhao, J. and Zhou, L., Qiu, M., Zhang. X., Yu. Z. and Yang, F. 2010. Antimicrobial activity of sphingolipids isolated from the stems of cucumber (Cucumis sativus L.). Molecules. 15, 9288-9297.

Yu, L., Haley, S., Perret, J., Harris, M., Wilson, J. and Qian, M. 2002. Free radical scavenging properties of wheat extracts. J. Agri.Food. Chem. 50, 1619-1624.

Zimmermann, M. 1983. Ethical guidelines for investigations of experimental pain in conscious animals. Pain. 16, 109. 